\title{
The Reliability of Epistemic Intuitions
}

Kenneth Boyd and Jennifer Nagel

\section{Introduction}

You see Plato running right past you. Unfortunately, you mistake him for Socrates, and you form the confident belief that Socrates is running, based on what you have seen. As it happens, just at this very moment Socrates is running, in a distant city. Do you know that Socrates is running?

Trusting his audience to share his feeling that knowledge is absent here, the $14^{\text {th }}$ century philosopher Peter of Mantua uses this example as ammunition against a theory according to which knowledge is just belief that is both confident and true (Boh, 1985). In doing so, he was engaging in a practice used by Eastern and Western philosophers from Plato's time to the present day: the practice of using epistemic intuitions-impressions about the presence or absence of knowledge, and the like-as evidence in epistemology. Is this practice legitimate? Do these feelings about particular instances of knowledge generally serve as a reliable guide to the nature of knowledge itself? This chapter argues that they do, and defends the practice of relying on intuitions against a variety of challenges.

The chapter starts with a brief overview of the nature of epistemic intuitions. Although people evaluate judgments along many dimensions of interest to epistemology, the main focus of this article will be on propositional knowledge attributions, immediate judgments of the form "Jane knows that John is running." Section two lays out some of the 
main reasons why we might expect intuitions about the presence and absence of knowledge to be reliable. Section three examines the challenge of skepticism, and discusses the difference between that challenge and the new challenge posed by nonskeptical experimentalists. Section four looks at evidence about variation in epistemic intuition across demographic groups such as ethnicity and gender. Section five looks at contextual variation in epistemic intuition, such as contrast effects. The final sections cover the impact of training in philosophy on epistemic intuitions, and the problem of variation among philosophers in epistemic intuition.

\section{The nature of epistemic intuitions}

We don't need to consult an explicit theory of knowledge in order to have the impression that someone knows something (or fails to know it). In describing epistemic intuitions as "immediate" we mean to contrast them with categorizations that require attention to a consciously available theory of the target concept. There are several signs that attention to an explicit theory of knowledge is not required when evaluating a case like the one above. First, in evaluating such cases we are not typically aware of any process of matching features of the case to features of a working theory of knowledge. It can sometimes be hard to say why one responded to a case as one did. Furthermore, it is possible for those who have a mistaken working theory of knowledge-such as Peter of Mantua's adversaries, perhaps-to find themselves responding intuitively to a novel case in a way which runs contrary to their working theory.

Intuitive judgments about knowledge and mere belief are not peculiar to philosophy. The words "know" and "think" are heavily used by ordinary people: they are 
the $8^{\text {th }}$ and $12^{\text {th }}$ most common verbs in English, and their counterparts are similarly common in other languages. All of the languages in the World Loanworld Database-a broad sampling of languages from every inhabited continent—report a word for "know" and "think," both in the sense that embeds a propositional complement (Haspelmath \& Tadmor, 2009). It is claimed that these verbs have the rare status of being "lexical universals," or terms with a precise (and typically one-word) translation in every natural language (Goddard, 2010). Children use both frequently, although "know" is acquired before "think" and used more heavily (Bartsch \& Wellman, 1995). The priority of knowledge attribution over belief attribution has been observed cross-culturally, both in work on the acquisition and use of the relevant verbs (e.g., Bassano, 1985; Tardif \& Wellman, 2000) and in work on children's abilities to make sense of situations in which a person either has or lacks knowledge (e.g., Liu, Wellman, Tardif, \& Sabbagh, 2008). From an early age, it is natural for human beings to make sense of others by thinking (and talking) about what they know, and what they don't know. If-as seems to be the case-we generally do this without any explicit reflection on the concept of knowledge, then epistemic intuition is a feature of our everyday social navigation.

\section{Why expect intuitions to be reliable?}

The fact that people frequently make intuitive judgments about knowledge does not on its own establish that those judgments tend to be accurate. Some patterns of judgment are common and broadly shared, but systematically out of line with reality-for example, people show a tendency towards unrealistic optimism about themselves, their future and their degree of personal control (Taylor \& Brown, 1988). Such illusions are not pervasive, 
however: interestingly, they are suppressed when we deliberate, and surge when we must act (Taylor \& Gollwitzer, 1995). Optimistic illusions are not helpful when we are figuring out what to do, but they serve a useful function in supporting confident action after a course of action has been decided. Those who are concerned about the reliability of epistemic intuition might wonder about the pressures towards accuracy or illusion shaping intuitive judgments about knowledge. Given that intuitive mechanisms are generally adaptive, a better understanding of the ordinary functions of epistemic intuition would help us answer this question.

Why do we have epistemic intuitions? The literature on mental state attribution identifies a variety of reasons why it is valuable for creatures like us to form rapid impressions about the presence or absence of knowledge. Animals living in social groups can better compete for resources (and keep control of them) when they are aware of whether their competitors do or do not know where the resources are located (Clayton, Dally, \& Emery, 2007; Hare, Call, \& Tomasello, 2001). More generally, the Machiavellian Intelligence Hypothesis (Whiten \& Byrne, 1988) has stressed that animals in complex social groups gain competitive advantages from mindreading: animals who are able to keep track of each others' underlying mental states do not simply expect the same surface patterns of behavior, but can more accurately anticipate changing behavior across changing circumstances. Specifically competitive settings have worked to elicit impressive performance in mental state attribution from nonhuman primates and young children (Kaminski, Call, \& Tomasello, 2008). In more cooperative settings-for example, in discriminating cues from 'helpers', some of whom knew where food was locatednonhuman animals have performed poorly (Povinelli, Rulf, \& Bierschwale, 1994). There is 
some evidence that nonhuman primates could sometimes gain advantages from recognizing each others' mental states in cooperative contexts (e.g. Russon, 1997), but the clearest evidence of cooperation eliciting mindreading comes from studies of humans. For example, eighteen-month old toddlers seem to compensate for an adult's false belief in trying to help him (Buttelmann, Carpenter, \& Tomasello, 2009).

Whether we are competing or cooperating, having accurate impressions of the epistemic states of others enables us to make better use of their expertise. If we can distinguish informants who are likely to know from those who are not, then the burden of gathering knowledge can be socially shared. In this vein, Sperber, Clement, Heintz, Mascaro, Mercier, Origgi, and Wilson have argued that mental state attribution plays a key role in 'epistemic vigilance', or our capacity to monitor the quality of what others communicate to us (Sperber et al., 2010). Developmental psychologists have shown that even very young children can apply their mindreading skills to distinguishing reliable from unreliable informants (e.g. Birch, Akmal, \& Frampton, 2009). On this view, one reason why humans greatly outperform other animals in their recognition of states of knowledge and belief would be that communication is much richer in human than nonhuman animals, warranting much more sensitive monitoring of its quality. The need for such monitoring constitutes one pressure towards accuracy in our intuitive attributions of knowledge.

Even experimentalists who challenge the reliability of epistemic intuitions sometimes explicitly grant that there could be a 'common core' of shared and reliable intuitions (e.g., Starmans \& Friedman, 2012; Weinberg, Nichols, \& Stich, 2001). For example, their studies feature control condition cases whose subjects are consistently and unproblematically judged not to know, such as cases involving subjects who possess 
justified but false beliefs or unjustified but true beliefs. Strong agreement about simple cases arguably makes it more plausible that weaker agreement on more subtle cases arises from incidental features of the task of evaluating these cases, such as difficulty in following the narrative.

Whether agreement in the common core of intuition itself counts towards the evidential value of intuition in epistemology depends in part on the extent to which epistemology is guided by intuitions about these simple cases. One might argue that philosophical work on knowledge only concerns subtle cases that are not immediately decidable on the basis of common and uncontroversially shared intuition. Subsequent sections will take a closer look at the question of whether intuitions do reliably decide subtle cases, but however that issue is decided, it is plausible that at least some less subtle cases still matter to epistemology. For example, one place that core intuitions have had a significant impact is in the battle with skepticism: if most epistemologists are inclined to resist skepticism, this is perhaps in part because it seems intuitive that we do have knowledge in ordinary cases of clear perception and sound inference. Epistemological skepticism has, however, raised a deep challenge to the reliability of intuition even in these cases, a challenge that merits further examination.

\section{The challenge of skepticism, and the new experimentalist challenge}

Skeptical philosophers typically acknowledge that we sometimes have the intuitive impression that someone has knowledge. Classical Pyrrhonian skeptics can be read as taking no position on the reliability of such impressions, and as simply counseling that judgment be withheld on all matters. By contrast, the typical contemporary skeptic argues 
that positive impressions about knowledge are unreliable, at least if taken literally. According to this skeptic, human beings rarely if ever have knowledge of anything; while we often say such things as "he knows that it is raining out," such claims are almost always literally false.

On closer examination, the role assigned to epistemic intuitions within contemporary skepticism is somewhat tricky, and perhaps unstable. A useful illustration can be found in Peter Unger's early skepticism. Unger explains our intuitions about knowledge by means of a parallel with our intuitions about flatness, a concept he takes to have a similarly "absolute" structure. If we take even microscopic bumps into account, almost nothing is literally flat, but various surfaces (fields, roads, tables) may come closer than others to the condition of actual or absolute flatness. Conceding that our ordinary positive judgments about what is flat are not literally true, Unger leaves it open that these judgments reliably capture truths about what is flat enough for our purposes. In Unger's analogy, where flatness demands the absence of bumps, knowledge demands the absence of doubts. He contends that knowledge is absolute in the sense of requiring complete certainty, or the complete absence of doubt (apparently including even potential doubt). According to Unger, anyone who is more certain that $2+2=4$ than that $56+45=101$ cannot count as being fully certain or doubt-free in the latter judgment, and therefore cannot count as knowing it. Read charitably, everyday attributions of knowledge to others amount to impressions that they have no actual or potential doubts that are relevant for our purposes, not that they have no actual or potential doubts whatsoever. Epistemic intuitions on this account do not track knowledge itself, but they do track some rough and purpose-relative 
approximation of knowledge, and might still count as having some reliability in the sense of conveying useful information.

Interestingly enough, at a decisive point in his argument Unger himself relies on intuition: in defending the notion that complete certainty is indeed required for knowledge, Unger appeals to the intuitions we have when the key terms are emphasized. He observes that even if we initially find it acceptable to say “He knows that it is raining, but he isn't certain of it," we have a "feeling of contradiction" in response to "He really knows that it is raining, but he isn't actually certain of it" (Unger, 1971, 216). He concludes from this feeling that certainty is required for knowledge. It is not obvious how a skeptic can be so confident that such feelings are reliable. Keith DeRose observes that there is an awkward asymmetry in the way the skeptic rejects all positive intuitions attributing knowledge while accepting negative intuitions about its absence (DeRose, 1995).

Still, if the skeptic is right that there are ways of eliciting negative intuitions about ordinary mundane claims to knowledge-for example, by reflecting on problematic possibilities concerning brains in vats-then the epistemologist who trusts intuitions will have to come up with an explanation of those negative feelings, and a story about how they fit with our more commonly positive feelings about the same judgments. One could follow DeRose himself in adopting contextualism, a view that takes the semantic content of the verb "know" to be variable, reflecting the concerns of the attributor of knowledge. On this view, intuitive claims about knowledge may be typically reliable, but their semantics is perhaps more complex than one might initially have imagined. It is also possible to advocate an error theory for the intuitions motivating skepticism, perhaps arguing that the skeptic's negative feelings arise from some psychological bias (Hawthorne, 2004; Nagel, 
2010; Williamson, 2005). Which approach is more satisfactory will presumably depend on factors going well beyond intuition itself, factors such as the internal coherence and empirical credentials of the relevant semantic, philosophical, or psychological theories.

The new experimentalist challenge to the reliability of epistemic intuitions is not a generic skeptical challenge: experimental philosophers are not simply arguing that knowledge is impossible, nor are they arguing that intuitive capacities generally have unreliable or meaningless deliverances (Weinberg, 2007). Their claim instead is that we have empirical evidence for the unreliability of epistemic intuition. A review of this evidence is in order.

\section{Demographic variation}

It has been claimed that epistemic intuitions vary according to ethnicity (Weinberg et al., 2001) and gender (Buckwalter \& Stich, 2011). In their 2001 study, Weinberg et al. reported that participants of East Asian heritage were less likely to ascribe knowledge to the protagonist of a version of Lehrer's Truetemp case than their western counterparts, and much more likely to ascribe knowledge in Gettier cases. Meanwhile, Buckwalter and Stich reported significant differences in male and female intuitions about a wide range of philosophical topics, including Gettier cases, where one study found female participants much more likely to ascribe knowledge than male participants. If people of differing ethnicity and gender disagree in their intuitions, then intuition-driven epistemology faces a

problem. Jonathan Ichikawa (forthcoming) calls the problem the "arbitrariness critique": since my ethnic and sexual characteristics are purely arbitrary, so therefore are my epistemic intuitions. If my intuitions are arbitrary, then I should not consider them to be 
any special guide to the truth. Weinberg et al. put the question pointedly as follows: if my intuitions depend on whatever ethnic or sexual group I happen to be a part of, "Why should we privilege our intuitions rather than the intuitions of some other group?" $(2001,45)$.

Many trusted sources of evidence have some arbitrary element: sensory perception, for example, typically has some margin of error, or some band within which judgments will vary arbitrarily. Experimentalists cannot criticize epistemic intuition simply on the grounds that not everyone reaches the same judgment at all times; a demand for perfect unanimity would be problematic for the sources of evidence that empirically-motivated research programs need to take for granted. Systematic variation correlated with ethnicity or gender is also not in itself a reason to discount a source of information. For genetic reasons, women may have slightly better color vision, as a group, than men do; for reasons having to do with visual climate, some ethnic groups have slightly better eyesight than others. On certain subtle color discrimination tasks, there will be variation correlated with gender: a larger majority of women than men will get the right answer. However, such a finding should not incline either group to conclude that their color judgments lack evidential value. Demographically correlated variation in a capacity is consistent with its general reliability. We are forced to choose between our intuitions and those of some other group only if the relevant intuitions are deeply at odds with each other.

To date, there is no robust evidence that the epistemic intuitions of different demographic groups are deeply at odds with each other. Although the Weinberg et al. (2001) results have been heavily cited, it is doubtful that they are robust. The suggestion that South Asians tend not to feel Gettier case intuitions is especially puzzling; as early as the $8^{\text {th }}$ century, South Asian philosophers developed cases very much like Gettier's-for 
example, cases in which someone infers a true conclusion from a false but reasonable belief-and reported that they took the subjects of such cases to lack knowledge (Matilal, 1986; Phillips, 2012; Stoltz, 2007). An effort to replicate the Weinberg et al. (2001) Gettier case results with multicultural North American participants failed to detect ethnically correlated differences in responding to Gettier cases (Nagel, San Juan, \& Mar, 2013). A more thorough effort to replicate all the Weinberg et al. (2001) epistemic case results with multicultural British participants also failed to turn up any ethnically correlated differences (Seyedsayamdost, ms-b). John Turri also reports a lack of difference in evaluations of Gettier cases in tests of Western participants and participants from the Indian subcontinent, as well as between male and female participants (Turri, 2013).

It would, we think, be surprising if it turned out that the Weinberg et al. (2001) results were robust, given existing evidence of cross-cultural similarities in the ways states of knowledge and belief are attributed. It has been claimed, however, that there is independent contrary evidence that should lead us to expect cross-cultural disagreement about knowledge. Weinberg et al. (2001) cite as one main source of inspiration for their study Nisbett's work on East-West differences in reasoning: the former group are said to favor more "holistic" reasoning, and the latter a more "analytic" style (Nisbett, Peng, Choi, \& Norenzayan, 2001). It's not obvious, however, how reasoning analytically rather than holistically would result in differences in epistemic intuitions, especially when facing Gettier cases, which are typically novel for study participants. Weinberg et al. mention that the Nisbett program has claimed that Westerners emphasize causation where Easteners emphasize similarity, and further observe that "in a large class of Gettier cases, the evidence that causes the target to form a belief turns out to be false" $(2001,442-443)$. 
However, it is not entirely obvious how knowledge attribution would differ as a function of increased attention to causation as opposed to similarity: while it is true that there is something causally abnormal about these cases, given that most inferential knowledge is not derived from false beliefs, these Gettier cases show an equally conspicuous failure of similarity to ordinary cases of knowledge. In the absence of a clear story about the mechanism linking East-West differences to Gettier case responses, the Nisbett program does not give us clear reason to expect differences one way or the other.

Furthermore, it is an assumption of the Nisbett program that members of both cultures have both ways of thinking available to them; the difference is supposed to be one of prevalence and tendency rather than capacity. Under conditions of similar motivation, and given similar prompts towards either analytic or holistic ways of thinking, members of either type of culture think in similar ways (Zhou, He, Yang, Lao, \& Baumeister, 2012). The pressures involved in thinking carefully about philosophical cases would arguably be similar for Eastern and Western people, producing similar patterns of reasoning (which could be one reason why the Nagel, Seyedsayamdost and Turri results did not show culturally-correlated divergence in epistemic intuition).

One could also challenge the empirical credentials of the Nisbett program itself: Some of its most epistemologically surprising claims, such as the claim that East Asians are tolerant of contradictions and weaker at rule-based reasoning, have not held up well under subsequent empirical testing, or even reanalysis of the original data (Friedman, Chen, \& Vaid, 2006; Lee, Johson-Laird, \& Sun, 2006; Unsworth \& Medin, 2005). There is reason to suspect that at least some of the differences originally announced by the Nisbett program were overstated. Meanwhile, abundant cross-cultural similarities give us some reason to 
think that epistemic intuitions are more likely to be in agreement than disagreement with each other. For example, there are robust similarities across cultures in the development of mindreading, or "the capacity to interpret, predict, and explain the behavior of others in terms of their underlying mental states" (Scholl \& Leslie, 1999, 132). Harris (1990) argues that available data "support the claim that the same theory of mind emerges universally in the young child with approximately the same time-table" (222) and Segal (1996) argues that cross-cultural studies indicate that theory of mind development is "identical across the species" (153). Similarly, Wellman, Cross, and Watson (2001) argue that performance on false-belief tasks "showed a consistent developmental pattern, even across various countries" (655). Work on cross-cultural differences in mindreading tends to focus on disparities in performance, rather than underlying competence; indeed it is stressed that the underlying competence is the same (e.g., Wu \& Keysar, 2007). Empirical literature on cross-cultural variation in mindreading does not support the contention that the basic structural features of knowledge are seen to differ between cultures. At the structural level, commonalities are emphasized: "We can presume that people in all cultures operate on the same fundamental principles - we are all sentient, we all have knowledge, beliefs, desires and intentions, and these mental states interact in essentially similar ways" (Apperly, 2011, 165). Against this background, and without any clear story about why people from different cultures would disagree about the nature of knowledge, the burden of proof seems to lie on those who expect cross-cultural disagreement in epistemic intuition.

Similarly, although women and men differ in certain cognitive and non-cognitive tasks, it is again not obvious whether, if at all, such differences would affect epistemic 
intuitions. Beyond the age of four, males and females in the non-clinical population do not seem to differ in the way they distinguish knowledge from ignorance and false belief (Charman, Ruffman, \& Clements, 2002). To argue that men and women differ in their intuitions, Buckwalter and Stich actively solicited reports from experimental philosophers who had encountered significant gender differences in their experiments on intuitions. However, we should expect this method to turn up some significantly different results simply by chance: on the assumption that there is no significant relationship between gender and intuition, most studies will show men and women responding similarly, but some will show women outperforming men, and others will show men outperforming women. To establish that men and women really differ, one would need to disclose the total pool from which the disparities were drawn, to show the proportion of cases in which differences were found; Stich and Buckwalter have not done this.

The quality of the relevant studies also matters: much emphasis has been placed on a conference presentation presenting a gender difference in Gettier case recognition (Starmans \& Friedman, 2009). Subsequent efforts to replicate that finding have failed (Seyedsayamdost, ms-a). Indeed, the authors of the 2009 presentation themselves regard their earlier finding as unrepresentative of male and female performance, and in a more recent and more detailed study they report no gender differences in epistemic intuitions (Starmans \& Friedman, 2012).

It is very unusual to find large gender differences on cognitive tasks. After conducting a comprehensive review of 46 meta-analyses on gender differences, Janet Hyde summarized the available data as supporting the "gender similarities hypothesis," according to which "males and females are similar on most, but not all, psychological 
variables" (Hyde, 2005, 581). The largest effect sizes in Hyde's meta-meta-analysis were found to be in motor performance and physical aggressiveness, that is, on non-cognitive tasks (586). If males and females generally perform similarly on various cognitive tasks, we might expect them to have similar epistemic intuitions. Indeed, Banerjee, Huebner, \& Hauser (2010) report just such cross-gender similarity in terms of intuitive moral judgments: they collected reports of intuitive moral judgments from over eight thousand subjects and found that while there was statistical significance in differences in the way that members of different genders responded in most scenarios, the overall effect size was "extremely small" (270).

It is possible that there is some robust, large and yet-to-be-discovered demographic variation in epistemic intuitions, but the thought of this mere possibility does not constitute a positive empirical reason to consider epistemic intuitions unreliable.

\section{Contextual variation}

In their (2008), Swain, Alexander, and Weinberg tested participants' intuitions about whether the main character of Lehrer's "Truetemp" case really knew what the temperature was, or only believed it. The case concerns a man whose brain has received a prosthetic brain implant that gives him precise beliefs about the temperature: unaware that his brain has been modified in this way, he finds himself reporting beliefs about the precise temperature, with no accompanying ideas about the credentials of these reports. The results of the study suggested that whether one reports the intuition that Truetemp has knowledge or only belief about the temperature correlates significantly with the order in which the case is presented. If the Truetemp case is presented immediately after a 
relatively clear case of ignorance-a case in which one claimed to know the result of a coin flip because of a "special feeling" — then subjects were much more likely to judge that Truetemp did, in fact, know what the temperature was. If, on the other hand, participants were first presented with a relatively clear case of knowledge-a case in which a chemist makes a well-informed judgment about the danger of mixing certain chemicals-they were less likely to judge that Truetemp had knowledge.

Interestingly, Swain et al. also tested the intuitions of participants about "Fake Barn" scenarios. This type of case can be described in a number of ways, but the classic example from Goldman (1976) concerns a man—call him Henry—who is driving through the country unaware that most of the things that look like barns are in fact mere facades. When Henry sees something that is in fact a barn and judges it to be one (but at such a distance he would have been taken in, had it been one of the nearby facades), does he know that he is then looking at a barn? Swain et al. found the results for this case to be much less susceptible to contextual variation than the Truetemp cases (146). Notwithstanding this stability, Swain et al. consider their results to pose a twofold problem for those reliant on epistemic intuitions. First, that epistemic intuitions are susceptible to contextual variation suggests that such intuitions are "unstable" because they are "susceptible to manipulation" (141). Of course, simply being susceptible to manipulation is not itself a reason to distrust intuition. Other faculties that we rely on are similarly susceptible, but are nevertheless generally considered trustworthy; an obvious example is our reliance on perception. Indeed, as they note, Ernest Sosa anticipates the objection that manipulability is a reason to distrust a faculty: 
One would think that the ways of preserving the epistemic importance of perception in the face of such effects on perceptual judgments would be analogously available for the preservation of the epistemic importance of intuition in the face of such effects on intuitive judgments. The upshot is that we have to be careful in how we use intuition, not that intuition is useless. (Sosa, 2007, 105)

However, Swain et al.'s second, and more significant, objection is that since certain intuitions seem to vary depending on context-e.g. the Truetemp cases-and others do not—-the Fake Barn cases-it's not clear which intuitions we can actually trust to remain stable and which we can't. In relying on perception we are generally able to distinguish situations in which our perception is manipulated from those in which it is functioning properly—the philosopher's favorite "normal lighting conditions." Swain et al. argue that the case of perception and intuition are thus disanalogous: “[a]t this time, we don't know what is the parallel for intuition of making sure the light is on; that is, we do not know which are the circumstances that render intuition reliable or unreliable" (148). Of course, they do not deny that we might be able to find that there is something specific about the Truetemp cases that makes them susceptible to contextual factors in a way that intuitions about other cases are not. However, if we are able to find out which intuitions are reliable and which are not, Swain et al. argue, it is not something that can be reasoned about $a$ priori: philosophers must get out of their armchairs to find the answers.

We take no issue with the suggestion that it would do philosophers some good to get out of their armchairs every once in a while. Once we are out of our seats, however, there is evidence that our intuitions may not be as unstable as Swain et al. make them out to be, and that we do possess resources that allow us to know when the intuitive lighting 
conditions are normal. In her (2010), Wright similarly found contextual variation in responses to Truetemp cases, and a lack of variation in responses to cases of "clear" knowledge or lack of knowledge (Swain et al.'s cases of testimonial inference and coin flips, respectively). The cases that elicited context-sensitive responses were dubbed "unstable," whereas those cases that did not elicit context-sensitive responses were dubbed "stable." Wright found, however, that participants reported "significantly more confidence when considering cases that elicited stable judgments than when considering cases that elicited unstable judgments, regardless of their order of presentation" (495) and had "significantly stronger beliefs (or, held their beliefs more strongly) about the stable cases than about the unstable cases" (500). Introspectively checking our confidence in an intuition that we possess might then be a good way of testing to see if the lighting conditions are normal. It is a general feature of intuitive judgment that more confident intuitive judgments are more likely to be stable within an individual and shared across populations (Koriat, 2012). Wright cautions, however, that while laypeople's reported confidence and belief strength is lower in unstable cases than in stable ones, this is not necessarily the case for professional philosophers. A staunch defender of reliabilism might claim that they are very confident and believe very strongly that Truetemp has knowledge, whereas a critic might claim to have the same degree of confidence and belief strength in exactly the opposite position. What might explain the difference in confidence levels between trained and untrained philosophers? One obvious difference is the training itself: Wright posits that trained philosophers might have more confidence in the "right" intuitions because they have a certain kind of expertise that the untrained do not. The next section takes a closer 
look at the idea that differences in intuition can be accounted for by differences in expertise.

\section{Training in philosophy}

Is there evidence that laypeople's intuitions are systematically different from those of philosophers? Starmans and Friedman (2012) have claimed that laypeople differ from philosophers in their attributions of knowledge: where trained philosophers recognize Gettier cases as involving justified true belief but a failure of knowledge, laypeople see only a special class of Gettier cases this way, and otherwise equate knowledge with justified true belief. The special class of Gettier cases are those about which an inference is made on the basis of what they call "apparent evidence," where a subject infers something true from a false but reasonably held belief.

Starmans and Friedman posit expertise as one possible explanation for this discrepancy. For example, they consider the possibility that "philosophers might be very practiced in thinking about the myriad ways in which the truth of belief might rest on luck" (10). Starmans and Friedman do not find this explanation very plausible, however, since they claim that due to the quantity of questions and the way that the scenarios were set up, the luck element was "obvious" to participants (10). In a similar vein, Weinberg, Gonnerman, Buckner, and Alexander (2010) argue that there is a problem with favoring philosophers' intuitions on the grounds of their expertise, where expertise is being "able to efficiently pick out just the epistemologically-relevant features of hypothetical cases." This characterization is so nondescript, they caution, that it will be hard to know whether one actually possesses expertise, or if it really makes any difference. According to Weinberg et 
al., the "explicitness and clarity" of other philosophical distinctions (e.g. the use/mention, epistemological/metaphysical, and semantic/pragmatic distinctions) "stands in very sharp contrast to the complete inarticulateness of the...well, whatever it would be, that is supposed to help trained philosophers to categorize Gettier cases as non-knowledge" (2010,342, ellipsis in original). Weinberg et al. do not argue that philosophers are wholly lacking in specialized professional expertise; for example, they explicitly grant that philosophers may have special skills in "the close analysis of texts" $(2010,335)$. There may be some room for the defender of epistemic intuition here. While it is true that we do not have a full theory of whatever it is that enables us to recognize Gettier cases, one might wonder whether the skill and motivation needed to attend to and analyze a difficult text could itself be part of what is involved in the ability "to efficiently pick out just the epistemologically relevant features of hypothetical cases" (cf. Williamson, 2011).

Furthermore, it is an open question just how much disagreement there is between professional philosophers and laypeople. For example, if we look more closely at the nature of the scenarios that Starmans and Friedman presented to their participants, we will find that it does not provide a strong case for the view that philosophers are unusual in their intuitions. Both of Gettier's original cases are clearly cases of inferring a true conclusion from a justified false belief (or "apparent evidence" cases, in Starmans and Friedman's terminology). For the epistemologist who relies on intuitions to guide and support their theory of knowledge, it would be heartening to read that the majority of lay participants are expected to agree with the standard verdict on the original Gettier cases. Starmans and Friedman cite Williamson (2005) as evidence that philosophers "with near unanimity" believe that subjects in Gettier cases do not have knowledge (9); however, 
Williamson is referring specifically to the response of philosophers to Gettier's original cases, a response which would be supported by Starmans and Friedman's results.

Starmans and Friedman did not actually test philosophers on the problematic cases in which laypeople unexpectedly attributed knowledge; instead, they support their contention that laypeople and philosophers would differ on these cases by noting structural similarities between these cases and some existing Gettier cases in the philosophical literature. One particular worry about the cases for which Starmans and Friedman found anomalous results is that they involved strange narratives in which an item is replaced with an identical duplicate behind a subject's back, and in at least some cases it is somewhat unclear whether the replacement might have been managed precisely to ensure that the state of the world after the substitution matches the subject's original state of mind. It is not obvious that these really are Gettier cases, or that philosophers would respond to them differently than the laypeople, or that any discrepancies in lay responses to these cases arise from a different lay grasp of knowledge as opposed to differences in how attentively laypeople and philosophers are construing these hard-tofollow cases. Further research may help us understand whether philosophers really are different in their intuitive responses for these cases, and if so, why.

Some philosophers have suggested that philosophers' intuitive responses may be shaped by their intellectual climate (e.g., Gendler \& Hawthorne, 2005). It is not clear, as a matter of empirical fact, whether this is true: they suggest that negative intuitions about Fake Barn cases may be traceable to some peculiarly philosophical pressures, but these intuitions have also been found in laypeople (Nagel et al., 2013; Wright, 2010). If philosophical climates do shape epistemic intuitions, this may or may not be a good thing. 
Perhaps the competition among theories of knowledge leads to a sharpening of the relevant intuitive capacities. If on the other hand the dominance of influential theories is driven primarily by factors unrelated to the truth of the claims they make, then perhaps any influence of philosophical climate on intuitions would diminish their reliability. However, there is no obvious reason to suppose that philosophical theories, unlike theories in other disciplines, tend to thrive for reasons completely unrelated to their truth. In any event it is not clear to what extent theoretical commitments alter one's epistemic intuitions. It is certainly possible to have intuitions that go against one's own working theory of knowledge; for example, Alvin Goldman shifted from his early causal theory of knowledge (1967) to his later reliabilist theory (1976) in part because he came up with certain examples that did not intuitively seem to be examples of knowledge, notwithstanding their conformity to his earlier theory. As far as we now know, it may even be that one's epistemic intuitions are wholly insulated from theoretical commitments in epistemology, as judgments in syntax appear to be insulated from theoretical commitments in syntactic theory (Sprouse \& Almeida, 2012; Sprouse, Schutze, \& Almeida, 2013). Further research could improve our understanding of the relationship between epistemological theory and epistemic intuition; meanwhile, the hypothetical possibility that intuitions could be shifted by theory is not in itself a reason to doubt the reliability of epistemic intuition.

\section{Disagreement among philosophers}

Philosophers sometimes report disagreement about particular cases. In epistemology, there has been particular controversy over whether subjects in "Fake Barn"-type cases lack 
knowledge (Millikan, 1984; Turri, 2011). Many, but not all, philosophers have reported the intuition that the subject does not have knowledge in these cases, and have diagnosed this verdict as arising from an implicit recognition that knowledge requires reliability, or more specifically safety from error: if a person knows, he could not easily have gone wrong in a similar case.

A split in intuitive reactions to this case might be taken as a sign that some people but not others operate with an implicit theory of knowledge according to which knowledge requires safety, and that common epistemic intuition is therefore powerless to decide the question. However, it is conceivable that discord is arising from incidental features of the case, rather than variation in implicit understandings of knowledge itself. The original story is arguably ambiguous about whether Henry's judgment is safe. The standard description of the case leaves it quite open exactly what risk Henry is exposed to, in part because it does not specify what kind of inquiry Henry is engaging in as he drives along, whether he is trying to make his mind up about everything he sees, and whether there is a serious chance of his looking at a fake barn at the moment he sees the real one. In support of such a line of thought, Keith DeRose observes that intuitions about this case are very sensitive to details about how it is fleshed out. For example, if we describe Henry as making a string of false "barn" judgments about a series of facades before he encounters the one real barn, it is easier to see that latter judgment as failing to exemplify knowledge (DeRose, 2009, 49).

Cases will not be informative if they simply stipulate their verdicts, but they must say enough to trigger an implicit classification of the judgment one way or the other. Because various details are inevitably left to the reader's imagination, many controversial 
cases lend themselves to a variety of different construals, and in some cases these differences can be epistemologically significant. For example, Jennifer Nagel (forthcoming) has argued that many of the cases involved in the clash between internalism and externalism—including the Truetemp case-are open to being read either as examples of knowledge or ignorance, depending on whether or not we represent the subject of the case as being self-conscious about the peculiarity of his belief formation; if internalists are inclined to read the case one way, and externalists another, they may not be giving different answers to the same question. If this approach is right, then greater care in our stipulations can produce greater uniformity in our subsequent epistemic intuitions. One of the difficulties involved in setting up a case is to say enough about the situation to ensure that one's reader will share one's understanding of its underlying facts; given that we do not yet fully understand the nature of knowledge, there is no quick formula to check that any given scenario has specified all the relevant facts in sufficient detail.

Even with all the relevant facts made clear, if epistemic intuitions still vary among individuals on certain cases, this is not necessarily a sign that intuition is generally unreliable. If some individuals have a form of color-blindness to certain types of problem, it would be hasty to conclude that intuitions should be seen as unreliable across the board. Contemporary epistemologists have conflicting rival theories but share a considerable band of common intuitions about philosophically interesting cases. On cases where intuition is divided, intuition can be retested on clearer and less ambiguous cases; intuition can also be corroborated or corrected by theoretical and empirical work in logic, psychology, semantics, and philosophy itself. Epistemic intuition is not infallible, but at 
present it looks reliable enough to continuing serving its traditional function of supplying us with valuable evidence about the nature of knowledge.

\section{References}

Apperly, I. (2011). Mindreaders: The cognitive basis of "theory of mind." Hove and New York: Psychology Press.

Banerjee, K., Huebner, B., \& Hauser, M. (2010). Intuitive moral judgments are robust across variation in gender, education, politics and religion: A large-scale web-based study. Journal of Cognition and Culture, 10, 253-281.

Bartsch, K., \& Wellman, H. (1995). Children talk about the mind. New York: Oxford University Press.

Bassano, D. (1985). Five-year-olds' understanding of 'savoir' and 'croire'. Journal of Child Language, 12, 417-432.

Birch, S. A. J., Akmal, N., \& Frampton, K. L. (2009). Two-year-olds are vigilant of others' nonverbal cues to credibility. Developmental Science, 13, 363-369.

Boh, I. (1985). Belief, justification and knowledge-Some late medieval epistemic concerns. Journal of the Rocky Mountain Medieval and Renaissance Association, 6, 87-103.

Buckwalter, W., \& Stich, S. (2011). Gender and the philosophy club. The Philosophers' Magazine, 52, 60-65.

Buttelmann, D., Carpenter, M., \& Tomasello, M. (2009). Eighteen-month-old infants show false belief understanding in an active helping paradigm. Cognition, 112, 337-342.

Charman, T., Ruffman, T., \& Clements, W. (2002). Is there a gender difference in false belief development? Social Development, 11, 1-10. 
Christensen, D. (2009). Disagreement as evidence: The epistemology of controversy.

Philosophy Compass, 4, 756-767.

Clayton, N. S., Dally, J. M., \& Emery, N. J. (2007). Social cognition by food-caching corvids.

The western scrub-jay as a natural psychologist. Philosophical Transactions of the Royal

Society B: Biological Sciences, 362, 507-522.

DeRose, K. (1995). Solving the skeptical problem. Philosophical Review, 104, 1-52.

DeRose, K. (2009). The case for contextualism: Knowledge, skepticism, and context, Volume 1.

New York: Oxford University Press.

Friedman, M., Chen, H. C., \& Vaid, J. (2006). Proverb preferences across cultures:

Dialecticality or poeticality? Psychonomic Bulletin \& Review, 13, 353-359.

Gendler, T. S., \& Hawthorne, J. (2005). The real guide to fake barns: A catalogue of gifts for your epistemic enemies. Philosophical Studies, 124, 331-352.

Goddard, C. (2010). Universals and variation in the lexicon of mental state concepts. In B. Malt and P. Wolff (Eds.), Words and the Mind (pp. 72-93). New York: Oxford University Press.

Goldman, A. (1967). A causal theory of knowing. The Journal of Philosophy, 64, 357-372. Goldman, A. (1976). Discrimination and perceptual knowledge. The Journal of Philosophy, 73, 771-791.

Hare, B., Call, J., \& Tomasello, M. (2001). Do chimpanzees know what conspecifics know? Animal Behaviour, 61, 139-151.

Harris, P. (1990). The child's theory of mind and its cultural context. In G. Butterworth \& P. Bryant (Eds.), Causes of development: Interdisciplinary perspectives (pp. 215-237). Hillsdate, NJ: Lawrence Erlbaum. 
Haspelmath, M., \& Tadmor, U. (2009). World Loanword Database. Max Planck Digital Library. Available: http://wold.livingsources.org/.

Hawthorne, J. (2004). Knowledge and lotteries. New York: Oxford University Press.

Hyde, J. S. (2005). The gender similarities hypothesis. American Psychologist, 60, 581.

Ichikawa, J. (forthcoming). Who needs intuitions? Two experimentalist critiques. In A.

Booth and D. Rowbottom (Eds.), Intuitions. Oxford: Oxford University Press.

Kaminski, J., Call, J., \& Tomasello, M. (2008). Chimpanzees know what others know, but not what they believe. Cognition, 109, 224-234.

Koriat, A. (2012). The self-consistency model of subjective confidence. Psychological Review, 119, 80-113.

Lee, N. Y. L., Johnson-Laird, P., \& Sun, R. (2006). Are there cross-cultural differences in reasoning? Proceedings of the 28th Annual Meeting of the Cognitive Science Society, 459-464. Liu, D., Wellman, H. M., Tardif, T., \& Sabbagh, M. A. (2008). Theory of mind development in Chinese children: A meta-analysis of false-belief understanding across cultures and languages. Developmental Psychology, 44, 523.

Matilal, B. K. (1986). Perception: an essay on classical Indian theories of knowledge. Oxford: Oxford University Press.

Millikan, R. (1984). Naturalist reflections on knowledge. Pacific Philosophical Quarterly, 65, 315-334.

Nagel, J. (2010). Knowledge ascriptions and the psychological consequences of thinking about error. Philosophical Quarterly, 60, 286-306.

Nagel, J. (forthcoming). Knowledge and Reliability. In H. Kornblith \& B. McLaughlin (Eds.), Goldman and his Critics. Oxford: Blackwell. 
Nagel, J., San Juan, V., \& Mar, R. (2013). Lay denial of knowledge for justified true beliefs. Cognition.

Nisbett, R., Peng, K., Choi, I., \& Norenzayan, A. (2001). Culture and systems of thought: Holistic versus analytic cognition. Psychological Review, 108, 291-310.

Phillips, S. H. (2012). Epistemology in Classical India: The knowledge sources of the Nyaya School. New York: Routledge.

Povinelli, D. J., Rulf, A. B., \& Bierschwale, D. T. (1994). Absence of knowledge attribution and self-recognition in young chimpanzees (Pan troglodytes). Journal of Comparative Psychology, 108, 74-80.

Russon, A. E. (1997). Exploiting the expertise of others. In R. W. Byrne \& A. Whiten (Eds.), Machiavellian intelligence II: Extensions and evaluations (pp. 174-206). New York: Oxford University Press.

Scholl, B. J., \& Leslie, A. M. (1999). Modularity, development and 'theory of mind'. Mind \& Language, 14, 131-153.

Segal, G. (1996). The modularity of theory of mind. In P. Carruthers and P. K. Smith (Eds.), Theories of theories of mind (pp. 141-157). Cambridge: Cambridge University Press.

Seyedsayamdost, H. (ms-a). On gender and philosophical intuition: Failure of replication and other negative results.

Seyedsayamdost, H. (ms-b). On normativity and epistemic intuitions: Failure of replication. Sosa, E. (2007). Experimental philosophy and philosophical intuition. Philosophical Studies, $132,99-107$.

Sperber, D., Clement, F., Heintz, C., Mascaro, O., Mercier, H., Origgi, G., \& Wilson, D. (2010). Epistemic vigilance. Mind \& Language, 25, 359-393. 
Sprouse, J., \& Almeida, D. (2012). Assessing the reliability of textbook data in syntax: Adger's core syntax. Journal of Linguistics, 48, 609-652.

Sprouse, J., Schutze, C., \& Almeida, D. (2013). A comparison of informal and formal acceptability judgments using a random sample from Linguistic Inquiry 2001-2010. Lingua.

Starmans, C., \& Friedman, O. (2009). Is knowledge subjective? A sex difference in adults. Paper presented at the 6th Biennial Meeting of the Cognitive Development Society, San Antonio, Texas.

Starmans, C., \& Friedman, O. (2012). The folk conception of knowledge. Cognition 124, 272283.

Stoltz, J. (2007). Gettier and factivity in Indo-Tibetan epistemology. The Philosophical Quarterly, 57, 394-415.

Swain, S., Alexander, J., \& Weinberg, J. M. (2008). The instability of philosophical intuitions: Running hot and cold on Truetemp. Philosophy and Phenomenological Research, 76, 138155.

Tardif, T., \& Wellman, H. M. (2000). Acquisition of mental state language in Mandarin-and Cantonese-speaking children. Developmental Psychology, 36, 25.

Taylor, S., \& Gollwitzer, P. (1995). Effects of mindset on positive illusions. Journal of Personality and Social Psychology, 69, 213-226.

Taylor, S. E., \& Brown, J. D. (1988). Illusion and well-being: a social psychological perspective on mental health. Psychological Bulletin, 103, 193.

Turri, J. (2011). Manifest failure: The Gettier problem solved. Philosophers' Imprint, 11, 111. 
Turri, J. (2013). A conspicuous art: putting Gettier to the test. Philosophers' Imprint 13:10, $1-16$.

Unger, P. (1971). A defense of skepticism. The Philosophical Review, 80, 198-219.

Unsworth, S. J., \& Medin, D. L. (2005). Cultural differences in belief bias associated with deductive reasoning? Cognitive Science, 29, 525-529.

Weinberg, J. M. (2007). How to challenge intuitions empirically without risking skepticism. Midwest Studies in Philosophy, 31, 318-343.

Weinberg, J. M., Gonnerman, C., Buckner, C., \& Alexander, J. (2010). Are philosophers expert intuiters? Philosophical Psychology, 23, 331-355.

Weinberg, J. S., Nichols, S., \& Stich, S. (2001). Normativity and epistemic intuitions. Philosophical Topics, 29, 429-460.

Wellman, H., Cross, D., \& Watson, J. (2001). Meta-analysis of theory of mind development: The truth about false belief. Child Development, 72, 655-684.

Whiten, A., \& Byrne, R. W. (Eds.). (1988). Machiavellian intelligence: Social expertise and the evolution of intelligence in monkeys, apes and humans. Oxford: Clarendon Press.

Williamson, T. (2005). "Armchair" philosophy, metaphysical modality and counterfactual thinking. Proceedings of the Aristotelian Society (Hardback), 105, 1-23.

Williamson, T. (2005). Contextualism, subject-sensitive invariantism and knowledge of knowledge. The Philosophical Quarterly, 55, 213-235.

Williamson, T. (2011). Philosophical expertise and the burden of proof. Metaphilosophy, 42, 215-229.

Wright, J. C. (2010). On intuitional stability: The clear, the strong, and the paradigmatic. Cognition, 115, 491-503. 
Wu, S., \& Keysar, B. (2007). The effect of culture on perspective taking. Psychological Science, 18, 600-606.

Zhou, X., He, L., Yang, Q., Lao, J., \& Baumeister, R. F. (2012). Control deprivation and styles of thinking. Journal of Personality and Social Psychology, 102, 460-478. 